\title{
Simple stochastic neuronal models and their parameters Petr Lansky
}

\author{
Address: Institute of Physiology, Academy of Sciences, Videnska 1083, 14220 Prague 4, Czech Republic \\ Email: Petr Lansky - lansky@biomed.cas.cz
}

from Eighteenth Annual Computational Neuroscience Meeting: CNS*2009

Berlin, Germany. 18-23 July 2009

Published: 13 July 2009

BMC Neuroscience 2009, I0(Supp| I):PII9 doi:I0.|I86/I47|-2202-I0-SI-PI I 9

This abstract is available from: http://www.biomedcentral.com//47I-2202/I0/SI/PI I 9

(c) 2009 Lansky; licensee BioMed Central Ltd.

The stochastic approach to the problems of computational neuroscience is common due to the apparent randomness of neuronal behavior. Many stochastic models of neurons have been proposed and deeply studied. They range from simple statistical descriptors to sophisticated and realistic biophysical models. On their basis, properties of neuronal information transfer are deduced. Simple stochastic neuronal models are investigated in the contribution.

The basic assumptions made on the spiking activity permit to consider spike trains as realizations of a stochastic point processes. Then, having the experimental data, the spike trains or membrane depolarization trajectories, we may ask what was the signal stimulating the neuron producing this sequence of action potentials. For this purpose, the parameters of the models have to be determined. The recent results achieved in both these directions and extending our previous effort [1-7] are summarized.

\section{References}

I. Greenwood PE, Lansky P: Information content in threshold data with non-Gaussian noise. Fluctuation and Noise Letters 2007, 7:79-89.

2. Hampel D, Lansky $P$ : On the estimation of the refractory period. J Neurosci Meth 2008, I 7 I:288-295.

3. Lansky P, Greenwood PE: Optimal signal estimation in neuronal models. Neural Comput 2005, 17:2240-2257.

4. Lansky P, Sanda P, He JF: The parameters of the stochastic leaky integrate-and-fire neuronal model. J Comput Neurosci 2006, 2I:2II-223.

5. Lansky P, Ditlevsen S: A review of the methods for signal estimation in stochastic diffusion leaky integrate-and-fire neuronal models. Biol Cybernet 2008, 99:253-262.
6. Bibbona E, Lansky P, Sacerdote L, Sirovich R: Errors in estimation of input signal for integrate-and-fire neuronal models. Phys RevE 2008, 78:011918.

7. Pawlas Z, Klebanov LB, Prokop M, Lansky P: Parameters of Spike Trains Observed in a Short Time Window. Neural Comput 2008, 20:1325-1343. 